\title{
Experimental Investigation on Mechanical Properties and Microstructure of Hybrid Copper Matrix Composites through Microwave Sintering Process
}

\author{
P. Karthick ${ }^{1 *}$, A. Abraham Eben Andrews' ${ }^{1}$ G. Muthuraj ${ }^{2}$ and A. Arun Raja ${ }^{1}$ \\ 'Department of Mechanical Engineering, Hindustan Institute of Technology and Science, Chennai - 603103, \\ Tamil Nadu, India; karthick.vetha@gmail.com, abrahamebenandrews@gmail.com, arunmechcsi@gmail.com \\ ${ }^{2}$ Department of Mechanical Engineering, SCAD College of Engineering and Technology, \\ Cheranmahadevi -627414, Tamil Nadu, India; muthuraj4565@gmail.com
}

\begin{abstract}
Objectives: To produce a metal matrix composite (MMC) using pure Copper as a base material reinforced with the ceramic additives each time with different volume fractions. Methods/Statistical Analysis: Copper MMCs, with varying particulate volume percentages using advanced microwave sintering techniques and report improvement in compressive strength, Hardness, Relative density properties with an increase in the reinforcement content. Findings: In this present experimental study, six different metal matrix composites specimen has been fabricated using pure copper ( $\mathrm{Cu}$ ) as a base material reinforced with silicon carbide (Sic) and graphite as one of the additives each time i.e., different volume fractions of Sic $(5 \%, 10 \%, 15 \%)$ and volume fractions of constant graphite $(5 \%)$. Powder state mixing technique was employed for the different constituent. After mixing, powders were poured in metallic die and then specimens are sintered through Microwave sintering $(2.45 \mathrm{GHz}, 3.2 \mathrm{~kW})$ with varying temperature $\left(850^{\circ} \mathrm{C} \& 900^{\circ} \mathrm{C}\right)$ and soaking time. Then various tests such as hardness, compressive and microstructure of the composite specimens have been carried out and it is observed that the sintering at $850^{\circ} \mathrm{C}$ has produced more effective fused matrix compared to rapid sintering at $950^{\circ} \mathrm{C}$ with high mechanical properties especially compressive strength has been improved for $850^{\circ} \mathrm{C}$ at $15 \%$ of Sic with $5 \%$ Graphite. Application/Improvements: Investigating the microwave sintering on physical, mechanical and microstructure changes of hybrid Copper matrix composite.
\end{abstract}

Keywords: Compressive Test, Copper, Graphite, Hardness Test, Microstructure Test, Microwave Sintering, Silicon Carbide

\section{Introduction}

Metal matrix composites utilize the properties of the matrix (light weight, good thermal conductivity, ductility) and of the reinforcement, usually ceramic (high stiffness, high wear resistance, low coefficient of thermal expansion $)^{1}$. By this way it is possible to obtain a material characterized, if compared to the basic metal component, by high values of specific strength, stiffness, wear resistance, fatigue resistance and creep, corrosion resistance in certain aggressive environments ${ }^{2}$. However, cause to the presence of the ceramic component, ductility, toughness and fracture to the coefficients of thermal expansion and thermal conductivity decrease. Many researchers attempted to sinter metal powder by microwave sintering ${ }^{3}$ and they made a comparative evaluation on mechanical properties of sintered metal powders such as $\mathrm{Fe}-\mathrm{Ni}$, $\mathrm{Fe}-\mathrm{Cu}$ and copper-TiC-graphite hybrid composites through microwave and conventional methods. Microwave sintered specimens exhibited better mechanical properties. Microwave sintered Fe-Ni exhibited a modulus of rupture which is $60 \%$ higher than the conventionally sintered ones. It has been reported that copper steel alloys could be sintered using microwaves. These alloys exhibited better mechanical properties than conventionally sintered ones.

${ }^{*}$ Author for correspondence 
Experimental study made on microwave sintering response of copper-graphite ${ }^{5}$. The problem of negative densification (expansion) through conventional sintering is surpassed by microwave sintering. Positive densification (shrinkage) was attributed to faster sintering which hinder the diffusion of tin particles into copper lattice. Experimental investigation made on magnesium based composites for the improvement of mechanical properties of microwave sintered $\mathrm{Al}$ and $\mathrm{Mg}$, to finer microstructure ${ }^{6}$. Microwave radiation is useful in material processing activities ${ }^{7}$ it has been reported that microwaves are used for joining of ceramic and composites. Like lasers, microwaves are used for glazing of alumina-titania composite ${ }^{8}$. Microwave sintering offers many advantages such as faster heating rate, lower sintering temperature, enhanced densification, smaller average grain size and an apparent reduction in activation energy in sintering. Some negative aspects of conventional sintering such as non-uniform heating, coarser microstructure and larger porosity can be minimized in microwave sintering ${ }^{9}$. The present study uses microwave hybrid heating for the development of metal matrix composites. Microwave hybrid heating comprises simultaneous actions of microwave and microwave coupled radioactive external heating, to realize the uniform and rapid heating ${ }^{10}$. Though some literature exists in microwave sintering of metal, no literature is available presently in the area of microwave sintering of copper based composites.

\section{Experiment}

\subsection{Materials}

Copper-Silicon Carbide-graphite composites were manufactured through powder metallurgy $(\mathrm{P} / \mathrm{M})$ route. Electrolytic copper powder having average grain size of $47 \mu \mathrm{m}$ was mixed with the Silicon Carbide $37 \mu \mathrm{m}$ size graphite powder of $50 \mu \mathrm{m}$ size. Copper powder was mixed with various volume fractions of Silicon carbide powder $5 \%, 10 \%, 15 \%$ And Graphite 5\%,10\% in manual pestle mortar for uniform mixing ${ }^{11}$. Table 1 shows composition of specimens. In order to obtain the proper mixing for duration of approximately $1 \mathrm{hr}$ is maintain for mixing the powders in the pestle mortar. Mixed powders were preheated at $150{ }^{\circ} \mathrm{C}$ in a muffle furnace to evaporate any volatile matter.
Table 1. Composition of specimens in $\%$

\begin{tabular}{|l|l|l|l|}
\hline Composite Specimens & Copper \% & SiC \% & Graphite \% \\
\hline Specimen 1 & 90 & 5 & 5 \\
\hline Specimen 2 & 85 & 10 & 5 \\
\hline Specimen 3 & 80 & 15 & 5 \\
\hline
\end{tabular}

\subsection{Composite Fabrication}

The D-2 Steel material was used for fabrication of die. D-2 Steel having high chromium content gives it corrosion resisting properties in the hardened condition and it possesses extremely high wear resisting properties. Dimension specification and fabricated die as shown in Figures 1-3. By using this die six different Compositions of specimens (shown in Table 2) has been fabricated. The preheated powders were uniaxially compacted in a CTM machine at a load of 20 ton to obtain cylinder shaped specimens having dimension of $15 \mathrm{~mm}$ diameter and $23 \mathrm{~mm}$ height with approximate pressure starts from $500 \mathrm{Mpa}$ to $1000 \mathrm{Mpa}$ for the plunger diameter of the die. Prior to sintering; the mixture was cold pressed into a cylindrical compact in a metal die of $15 \mathrm{~mm}$ in diameter under an axial pressure of $280 \mathrm{MPa}$ using die shown in Figure $4^{12}$.

\subsection{Microwave Sintering and}

\section{Characterizations}

The green compacts were kept inside the hybrid microwave sintering setup. Preliminary sintering trials were

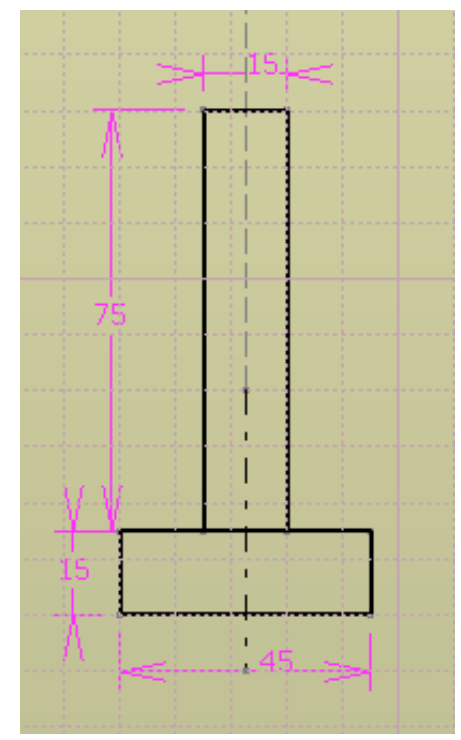

Figure 1. Dimension specification plunger. 


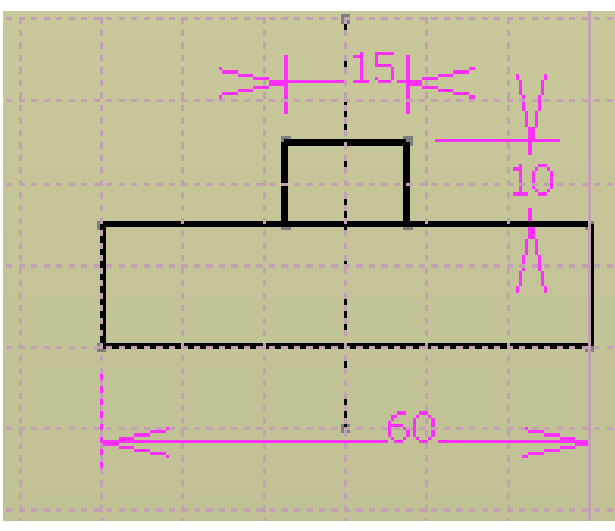

Figure 2. Dimension specification Base.

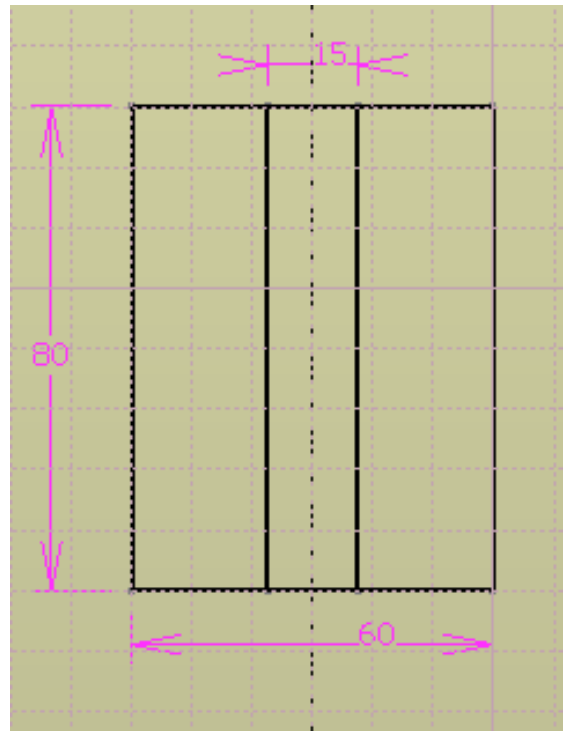

Figure 3. Dimension specification sleeve.

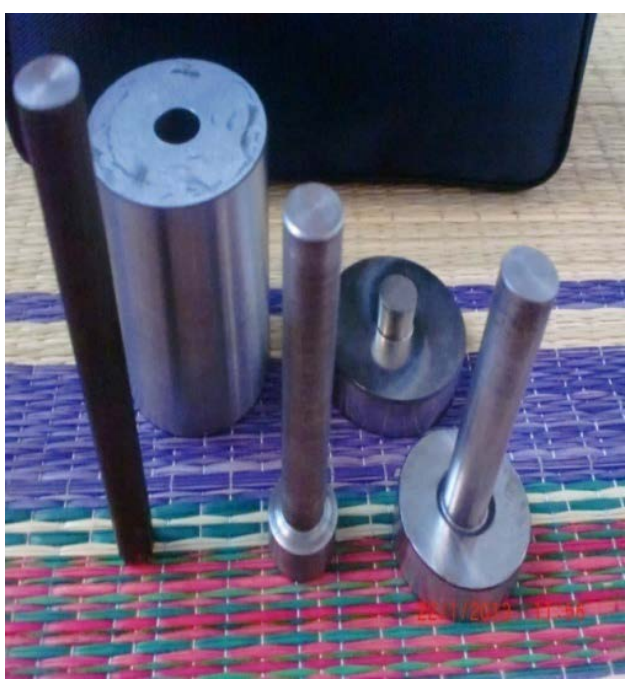

Figure 4. Photography of Die.

conducted for the sintering temperature range of $850{ }^{\circ} \mathrm{C}$ and $900{ }^{\circ} \mathrm{C}$ and isothermal holding time range of $10-60$ min. Sintering condition which emerged from the trial experiment has been extended to copper with various volume fractions of Sic and graphite composite. The microwave simultaneously interact with the green body sample, i.e. couple with green body sample and generates the heat internally due to penetrating feature of microwave in powder compacted samples. Two sets of green samples were sintered for each condition in order to assess the variation in processing and for the reproducibility of final properties. In all the cases, the power of microwave was controlled to $20 \%$ of maximum available power and the heating rate was also set within $25^{\circ} \mathrm{C} / \mathrm{min}$ for one set

Table 2. Fabrication and sintering of composite specimens

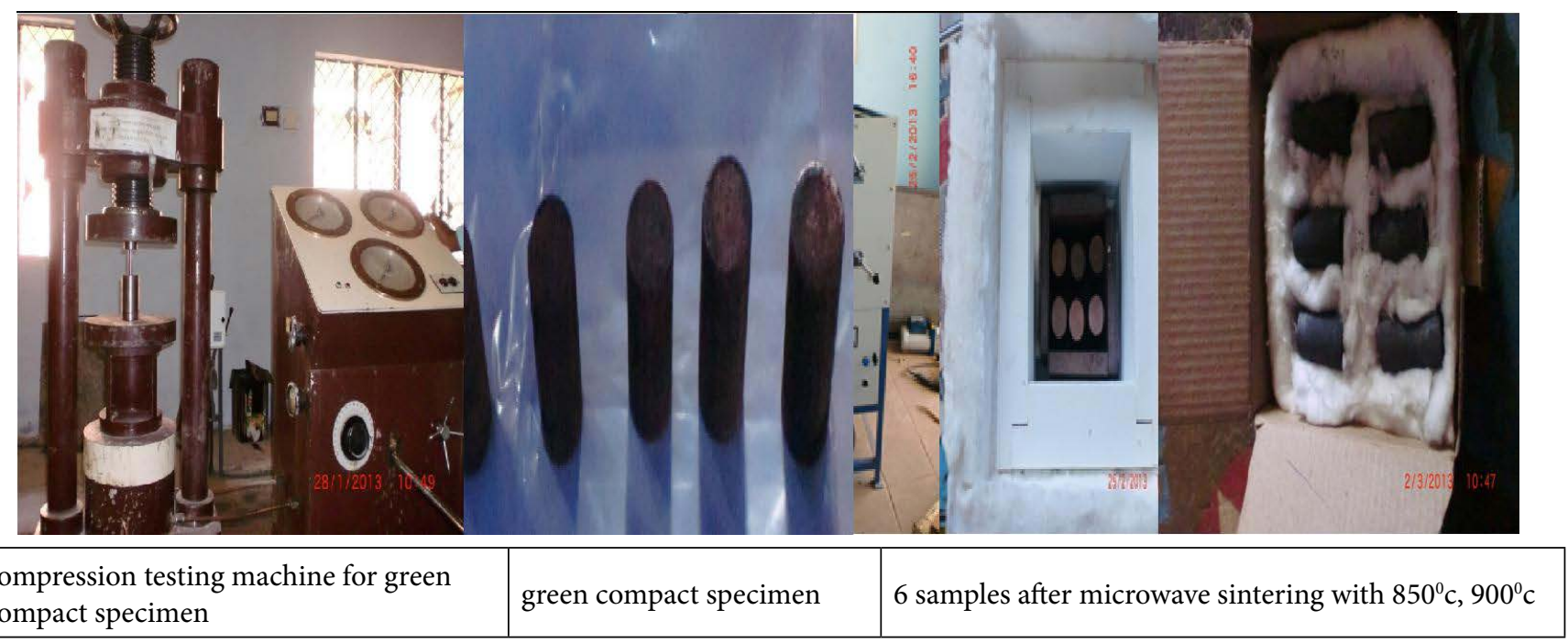


of samples for 60 mins. at $850^{\circ} \mathrm{C}$ and another samples at $50^{\circ} \mathrm{C} / \mathrm{min}$ for $10 \mathrm{mins}$ at $900^{\circ} \mathrm{C}$ that is rapid fast. After the definite isothermal holding time, the samples were allowed to cool in the furnace ${ }^{13}$. A $3.2 \mathrm{~kW}$ industrial microwave furnace $(2.45 \mathrm{GHz})$ was used in this study. Microwave sintering setup was designed to have two layers of elements, i.e. one is transparent to microwave and the other is absorber of microwaves for uniform heating. The alumina wool (transparent to microwave) was used for preserving the heat inside the crucible $\mathrm{SiC}$ fencing was used as a susceptor (microwave absorbing element). $\mathrm{SiC}$ fencing not only provides hybrid heating facility but also reduces the thermal gradient and this promotes crack free components ${ }^{14}$. Accurate temperature of samples was monitored using a ' $\mathrm{K}$ ' type thermocouple. The microwave sintering setup used in the present investigation and shown in Figure 5.

\subsection{Physical Property}

\subsubsection{Density Test}

Density test is done for finding the theoretical density and sintered density using the following formula to find out the Percentage of the theoretical density of the every sample for different composition. Density of the composites was measured by using Archimedes principle.

(i) Theoretical density $=(\rho$ of $\mathrm{Cu} x \mathrm{Vd}$ fraction of the $\mathrm{Cu})+(\rho$ of $\mathrm{SiC} x$ Vd fraction of the $\mathrm{SiC})+(\rho$ of $\mathrm{Gr}$ $\mathrm{x}$ Vd fraction of the $\mathrm{Gr}$ )

(ii) Sintered Density = (Weight of sample in air / loss of sample weight) $x$ Density of Water.

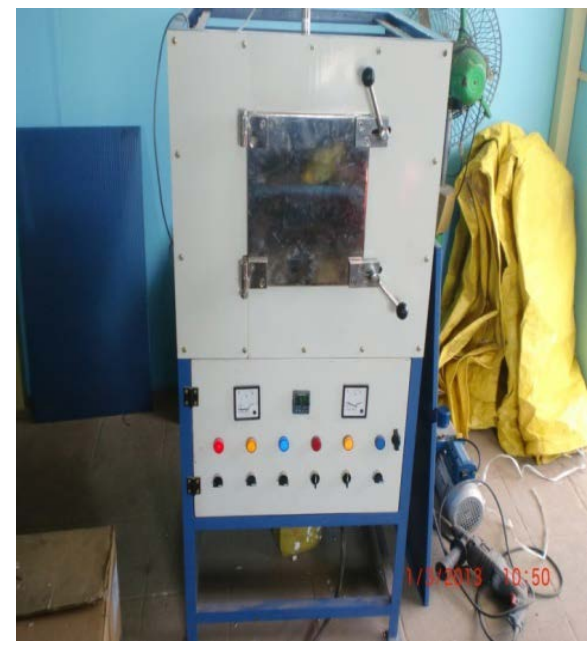

Figure 5. Microwave sintering machine.

\subsubsection{Hardness Test}

Hardness test was carried out on Vickers's micro hardness testing machine. Prior to the hardness test both side of the specimens were polished with emery paper to ensure for even distribution load. Testing load range: 10 grams to 1 Kgf Load; Vernier caliper least count: $0.01 \mathrm{~mm}$; Available Hardness testing Scale: HV 15N, 30N etc., are specifications of the machine.

\subsubsection{Compression Test}

Compression test was carried out on Universal testing machine. Prior to the compression test both side of the specimens were polished with emery paper to ensure for even distribution load. Lubrication was done by applying the grease on both sides of the sample so that the load could transfer without any Discontinuity and to minimize the friction at the interface and finally change in dimensions along the length and diameter was noted at the load and the corresponding true stress verses true strain data was plotted to obtain flow curve in accordance with equation (1). Testing load range: Max $50 \mathrm{kN}$.

$$
\sigma=\mathbf{k} \varepsilon \mathbf{n}
$$

Where $\sigma=$ True stress in MPa ; $\mathrm{k}=$ True strength; $\mathrm{n}=$ Strain Hardening exponent

\subsubsection{Microstructure Test}

Internal micro structures of composite specimens were studied by optical microscope. Prior to this test Potassium Dichromate Solution as Reagent (for copper) applied on both sides of the samples for 10-30 $\mathrm{sec}^{15}$. They microstructure test result on composite specimens.

\section{Results and Discussion}

\subsection{Investigation of Density Test Result}

Density study shows a decreasing trend with increase in content of Silicon carbide. The percentage of theoretical density increased with increasing in sintering temperature soaking time for a particular composition. It may be due to better bonding as shown in Figure 6. Composition of $\mathrm{SiC}$ varied (5-15\%) with Constant Graphite (5\%).

\subsection{Investigation of Hardness Test Results}

Hardness study shows an increasing trend with increase in content of Silicon carbide. The temperature without 


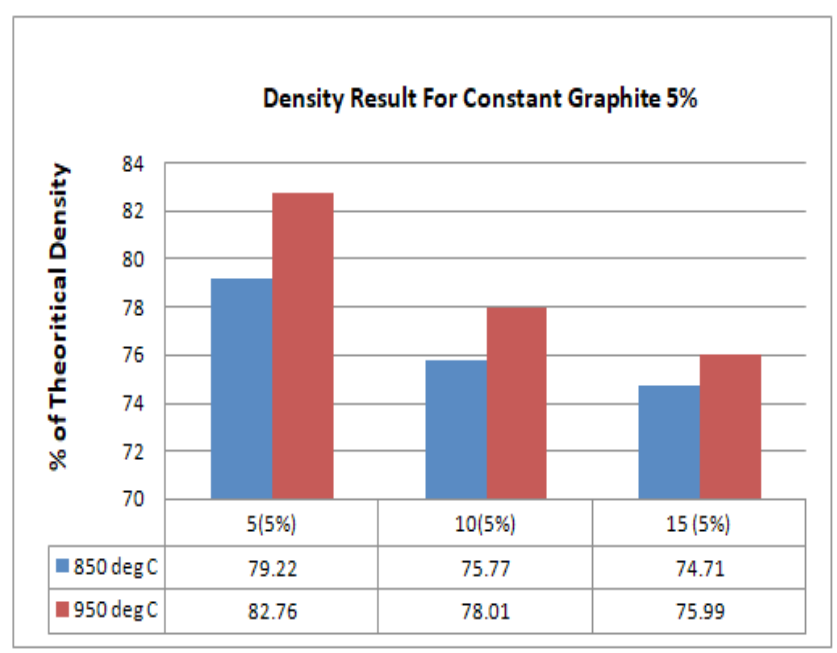

Figure 6. Density Result for Constant Graphite 5\%.

soaking time shows the decreasing in Hardness value compare to low temperature with soaking time. This effect is due to the better diffusion bonding between the materials during low temperature with soaking time during the microwave sintering. The Vickers's Hardness Number (VHN) increases with the increase in SiC composition at $850^{\circ} \mathrm{C}$ sintering temperature. The Vickers's Hardness Number also increased with the increase in sintering temperature for a particular composition of $\mathrm{SiC}$ with $5 \%$ of graphite with slight exceptions at 900 ${ }^{\circ} \mathrm{C}$ possibly due to impurities present or due to nonuniform heat distribution of $\mathrm{SiC}$ throughout the copper matrix Figure 7.

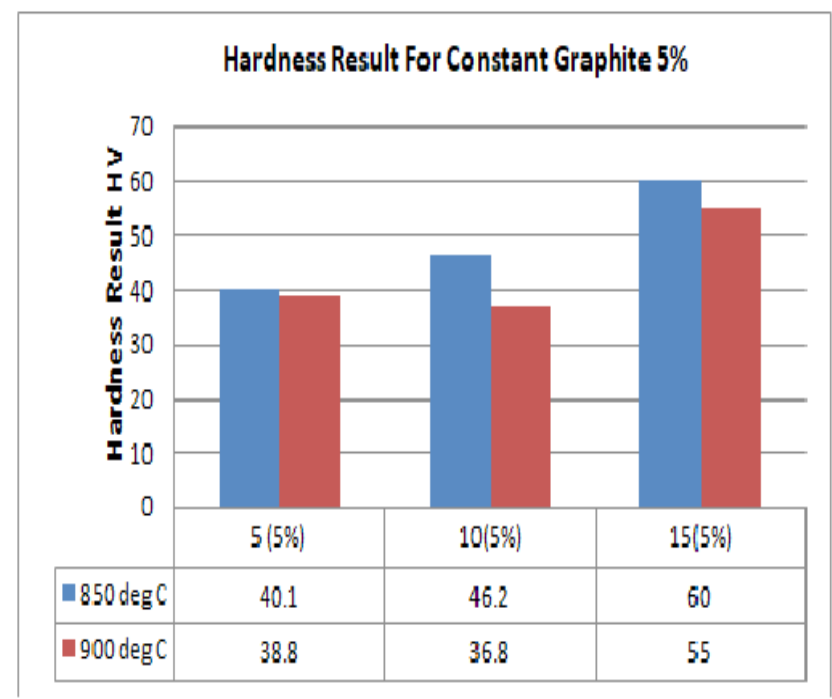

Figure 7. Hardness test Result for Constant Graphite 5\%.

\subsection{Investigation Compressive Test Results}

Compressive strength of each composition is proved through the compressive strength machine it is also known as crush testing machine which is computerized one with the help of FEI software the breaking loads are calculated and compared and the displacement analysis also taken for the comparison numerical analysis. Maximum compressive strength is obtained at $15 \mathrm{vol}$. $\% \mathrm{SiC}$ and const. 5 vol\% of graphite reinforced $\mathrm{MMC}$ at $850^{\circ} \mathrm{C}$ with soaking time. It is observed that the compressive strength at 850 degrees with soaking time has produced more effective strength than the 900 degree with rapid fast that is without soaking time. From the value it is observed that the compressive strength at 850 degrees with soaking time has produced more effective strength than the 900 degree with rapid fast that is without soaking time. Figures 8-9 shows the result of Break load and Ultimate load in $\mathrm{kN}$ and $\mathrm{kN} / \mathrm{mm}^{2}$.

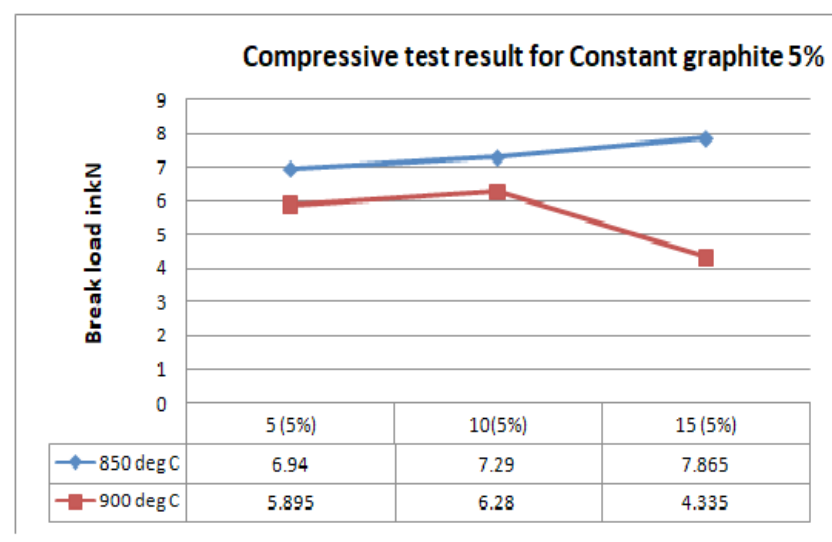

Figure 8. Compressive test Breaking load Result for Composition of Varying SiC (5-15\%) Constant Graphite 5\%.

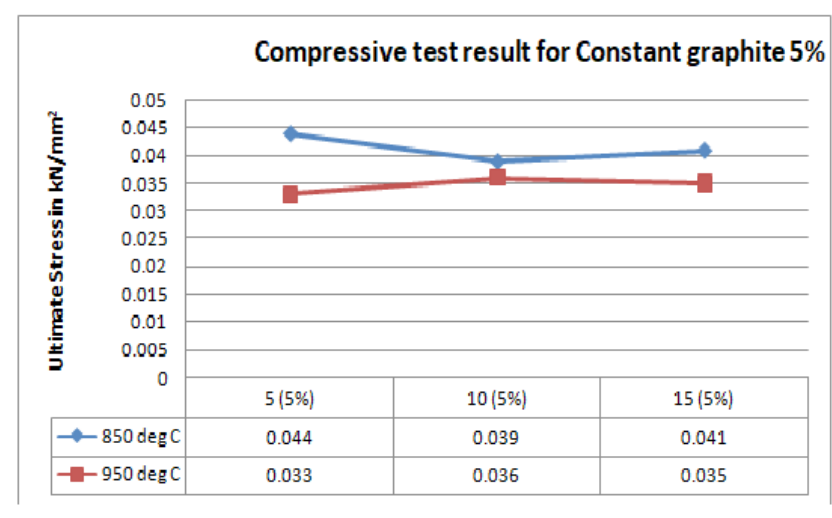

Figure 9. Compressive test Ultimate stress result for Composition of Varying SiC (5-15\%) Constant Graphite 5\%. 


\subsection{Investigation of Microstructure Result}

Figure 10 shows that at $850^{\circ} \mathrm{C} 5 \%$ of $\mathrm{SiC}$ Two fields have been captured for images of the microstructure. The photo micrographs shows the completely fusion areas during sintering with negligible quantum of Free copper left un-fused. The matrix also shows the presence of grey particles of Sic and dark agglomerated particles of free graphite in the copper matrix. The sintered matrix of copper shows very fine equi-axed grains of copper. Figure 11 shows that at $850^{\circ} \mathrm{C} 10 \%$ of $\mathrm{SiC}$ Two fields have been captured for images of the microstructure. The photo micrographs shows the completely fusion areas during sintering with negligible quantum of Free copper left un-fused. The matrix also shows the presence of grey particles of Sic and dark agglomerated particles of free graphite in the copper matrix. The sintered matrix of copper shows very fine equi-axed grains of copper. As more percentage of $\mathrm{SiC}$ is mixed large and fine particles of $\mathrm{SiC}$ is distributed in the matrix. Figure 12 shows that at $850^{\circ} \mathrm{C} 15 \%$ of $\mathrm{SiC}$ Two fields have been captured for images of the microstructure. The photo micrographs shows the completely fusion areas during sintering with negligible quantum of Free copper left un-fused.

The matrix also shows the presence of grey particles of Sic and dark agglomerated particles of free graphite in the
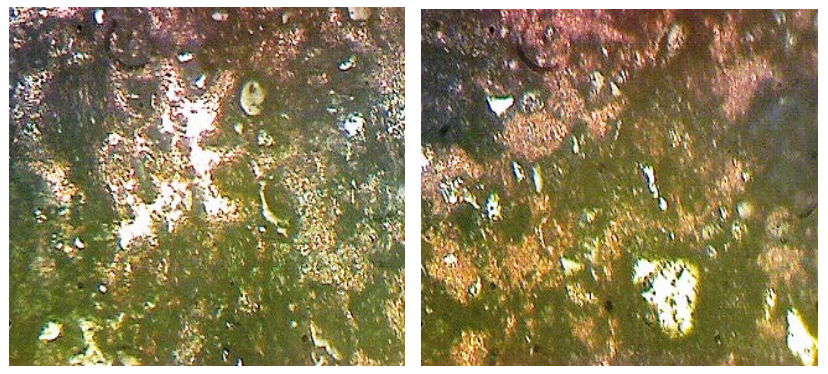

Figure 10. At $850^{\circ} \mathrm{C}$ Magnification: 200X Etchant: Pot. Dichromate Solution.
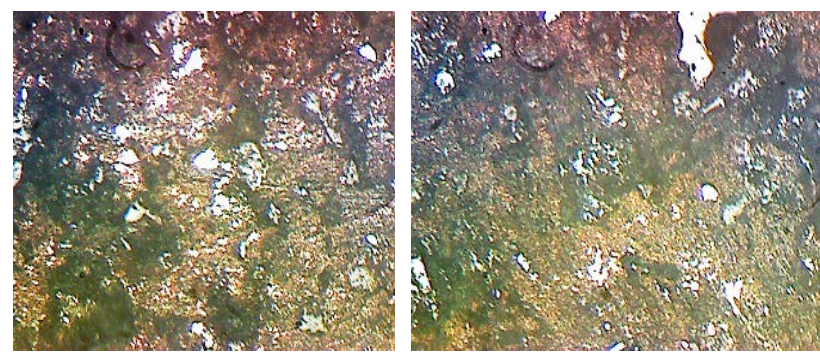

Figure 11. At $850^{\circ} \mathrm{C}$ Magnification: 200X Etchant: Pot. Dichromate Solution.
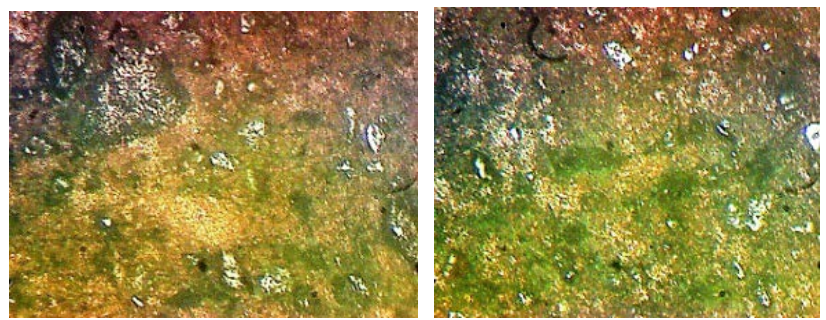

Figure 12. At $850^{\circ} \mathrm{C}$ Magnification: 200X Etchant: Pot. Dichromate Solution.

copper matrix. The sintered matrix of copper shows very fine equi-axed grains of copper. As more percentage of $\mathrm{SiC}$ is mixed large and fine particles of $\mathrm{SiC}$ is distributed in the matrix. Figure 13 shows that at $900^{\circ} \mathrm{C}-5 \% \mathrm{SiC}$ Two fields have been captured for images of the microstructure. The photo micrographs shows the completely fusion areas during sintering with negligible quantum of Free copper left un-fused. The matrix also shows the presence of grey particles of Sic and dark agglomerated particles of free graphite in the copper matrix. The sintered matrix of copper shows very fine equi-axed grains of copper. As more percentage of $\mathrm{SiC}$ is mixed large and fine particles of $\mathrm{SiC}$ is distributed in the matrix. Figure 14 shows that at $900^{\circ} \mathrm{C}-10 \% \mathrm{SiC}$ Two fields have been captured for images of the microstructure. The photo micrographs shows the
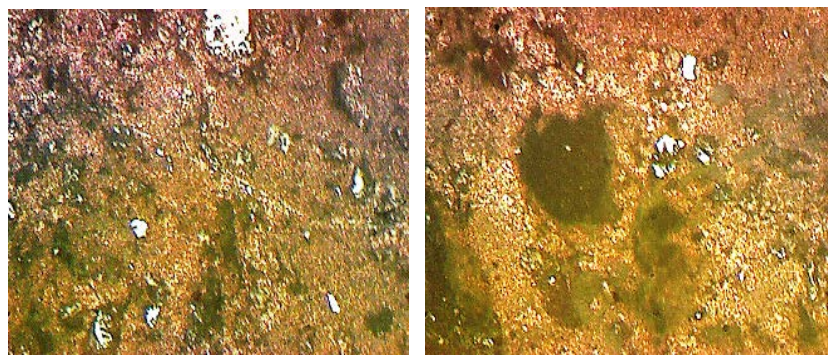

Figure 13. At $900^{\circ} \mathrm{C}$ Magnification: 200X Etchant: Pot. Dichromate Solution.
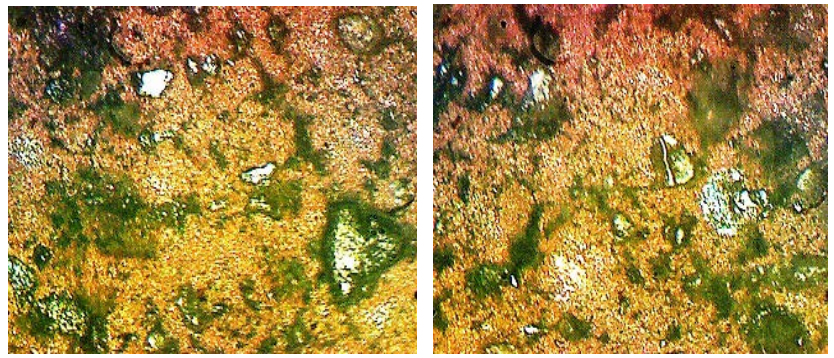

Figure 14. At $900^{\circ} \mathrm{C}$ Magnification: 200X Etchant: Pot. Dichromate Solution. 

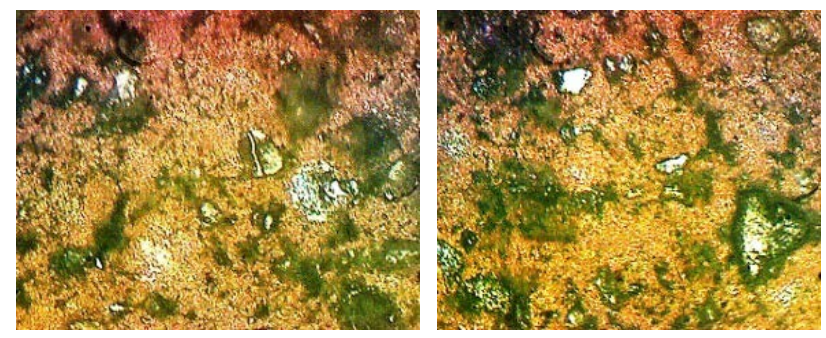

Figure 15. At $900^{\circ} \mathrm{C}$ Magnification: 200X Etchant: Pot. Dichromate Soln.

completely fusion areas during sintering with negligible quantum of Free copper left un-fused.

The matrix also shows the presence of grey particles of Sic and dark agglomerated particles of free graphite in the copper matrix. Figure 15 shows that at $900^{\circ} \mathrm{C}-15 \% \mathrm{SiC}$. Two fields have been captured for images of the microstructure. The photo micrographs show the completely fusion areas during sintering with negligible quantum of Free copper left un-fused. The matrix also shows the presence of grey particles of Sic and dark agglomerated particles of free graphite in the copper matrix. The sintered matrix of copper shows very fine equi-axed grains of copper. Only large grains of copper are left unfused Density study shows and decreasing trend with increase in content of Silicon carbide. The percentage of theoretical density increased with increasing in sintering temperature soaking time for a particular composition that may be due to better bonding as shown in Figure 6 .

\section{Conclusion}

The following conclusions can be drawn from the present investigation:

- The copper-Silicon carbide-graphite composites were successfully fabricated by microwave sintering process.

- (a) The percentage theoretical density decreased with the increase in $\mathrm{SiC}$ and graphite content of the different samples sintered at a low temperature with soaking time where the percentage theoretical density is decreased too short at a high temperature without soaking time.

(a) The percentage theoretical density increased with the soaking time with sintering temperature for a particular composition of the composite due to better bonding between the particles and reduction in the number of voids at low temperature with soaking time.

- (a) The Vickers's Hardness Number (VHN) increases with the increase in $\mathrm{SiC}$ composition at $850^{\circ} \mathrm{C}$ sintering temperature. Few deviations occurred like slight decrease in hardness with increase in $\mathrm{SiC}$ percentage at the same sintering temperature mainly due to the presence of unwanted impurities like oxygen, nitrogen, etc.

- (a) The Vicker's Hardness Number also increased with the increase in sintering temperature for a particular composition of $\mathrm{SiC}$ with $5 \%$ of graphite with slight exceptions at $900{ }^{\circ} \mathrm{C}$ possibly due to impurities present or due to non-uniform heat distribution of $\mathrm{SiC}$ throughout the copper matrix.

- The mixing of composite powder mixture results in very fine and homogeneously distribution of reinforcement throughout the matrix which is studied by microstructure test. It is observed that the sintering at $850^{\circ} \mathrm{C}$ has produced more effective fused matrix compared to rapid sintering at $950^{\circ} \mathrm{C}$.

- Maximum compressive strength is obtained at 15 vol. \% SiC and const. 5 vol\% of graphite reinforced $\mathrm{MMC}$ at $850^{\circ} \mathrm{C}$ with soaking time. It is observed that the compressive strength at $850^{\circ} \mathrm{C}$ with soaking time has produced more effective strength than the 900 degree with rapid fast that is without soaking time.

\section{References}

1. Tsai JL, Tu JF. Characterizing mechanical properties of graphite using molecular dynamics simulation. Materials and Design. 2010; 31(10):194-9. https://doi.org/10.1016/j. matdes.2009.06.032

2. Sanders RE. Kirk-Othmer Encyclopaedia of Chemical Technology, 5th Edition. Wiley-Interscience, John Wiley and Sons, Inc., New Jersey. 2004; p. 1-864.

3. Rajkumar K, Aravindan S. Tribological performance of microwave sintered copper-TiC-graphite hybrid composites. Tribology International. 2011; 44(4):347-58. https:// doi.org/10.1016/j.triboint.2010.11.008

4. Fathy A, Shehata F, Abdelhameed M, Elmahdy M. Compressive and wear resistance of nanometric alumina reinforced copper matrix composites. Materials and Design. 2012; 36:100-7. https://doi.org/10.1016/j.matdes.2011.10.021 
5. Rajkumar K, Aravindan S. Microwave sintering of copper-graphite composites. Journal of Materials Processing Technology. 2009; 209(15-16):5601-5. https://doi. org/10.1016/j.jmatprotec.2009.05.017

6. Gupta M, Wong WLE. An insight into processing and characteristics of magnesium based composites. Magnesium Technology. 2014; p. 423-8.

7. Dewidar MM, Lim JK. Manufacturing Processes and Properties of Copper-Graphite Composites Produced by High Frequency Induction Heating Sintering. Journal of Composite Materials. 2007; 41(18):2183-94. https://doi. org/10.1177/0021998307074145

8. Chandrasekaran S, Basak T, Ramanathan S. Experimental and theoretical investigation on microwave melting of metals. Journal of Materials Processing Technology. 2011; 211(3):4827. https://doi.org/10.1016/j.jmatprotec.2010.11.001

9. Chandrasekaran S, Ramanathan S. Microwave material processing - a review. AICHE Journal. 2012; 58:330-63. https://doi.org/10.1002/aic.12766

10. Ramesh CS, Ahmed RN, Mujeebu MA, Abdullah MZ. Development and performance analysis of novel cast copper-SiC-Gr hybrid composites. Materials and Design. 2009; 30(6):1957-65. https://doi.org/10.1016/j.matdes.2008.09.005

11. Efe GC, Yener T, Altinsoy I, Ipek M, Zeytin S, Bindal C. The effect of sintering temperature on some properties of $\mathrm{Cu}-\mathrm{SiC}$ composite. Journal of Alloys and Compounds. 2011; 509(20):6036-42. https://doi.org/10.1016/j.jallcom.2011.02.170

12. Alaneme KK, Sanusi KO. Microstructural characteristics, mechanical and wear behaviour of aluminium matrix hybrid composites reinforced with alumina, rice husk ash and graphite. Engineering Science and Technology, an International Journal. 2015; 18(3):416-22.

13. Reddy GC, Rajkumar K, Aravindan S. Fabrication of copper-TiC-graphite hybrid metal matrix composites through microwave processing. The International Journal of Advanced Manufacturing Technology. 2010; 48(5-8):64553. https://doi.org/10.1007/s00170-009-2474-0

14. Efe GC, Ipek M, Zeytin S, Bindal C. An investigation of the effect of $\mathrm{SiC}$ particle size on $\mathrm{Cu}-\mathrm{SiC}$ composites. Composites Part B: Engineering. 2012; 43(4):1813-22. https://doi.org/10.1016/j.compositesb.2012.01.006

15. Ullbrand JM, Cordoba JM, Tamayo-Ariztondo J, Elizalde MR, Nygren M, Molina-Aldareguia JM, Oden M. Thermomechanical properties of copper-carbon nanofibre composites prepared by spark plasma sintering and hot pressing. Composites Science and Technology. 2010; 70(16):2263-8. https://doi.org/10.1016/j.compscitech.2010.08.016 